\title{
GUEST EDITORIAL Imperatives, Strategies, and the World Campaign for The Biosphere
}

n new Delhi, India, in June of this year, and subsequently at Lake Louise, Canada, in October, a total of more than two hundred
scholars and educators met to define the focus of a new international environmental education programme. The occasions
were the first two regional workshops of the World Council For The Biosphere (WCB) and its sister organization the International
Society For Environmental Education (ISEE). The emerging programme is ISEE's part in the taking-on of the World Campaign
for The Biosphere. The discussions and recommendations from these workshops are being compared, contrasted, and synthesized,
jointly by the workshop directors and others, and will be reported on later in this issue of our sponsoring Journal which is featuring
WCB-ISEE. Therefore, I will not attempt such a summary here, but, instead, propose to focus on the mission of the World
Campaign for The Biosphere by looking at three words that were prominent in discussions in New Delhi and at Lake Louise. Campaign for The Biosphere by looking at three words that
These words are 'campaign', 'imperatives', and 'strategies'.

By definition, a campaign is a series of military or other operations that are undertaken to achieve a specific objective within a particular area, or an operation undertaken - often by means of propaganda—to attain some political, social, or commercial, goal. Does this fit the World Campaign For The Biosphere? Certainly we are not a military operation, although there have been militant moments and even actions in the environmental movement. We do have objectives, and we are trying to attain political, social, and even commercial, goals. Our objectives tend to focus on particular areas, for, following the cliché often attributed to the late René Dubos, we think globally but act locally. This much of the definition does seem to describe what we are attempting with the Campaign.

But, I am concerned about the implications of 'propaganda', and must admit that environmental education has often bordered on being propaganda. This is a significant danger whenever educators promote a particular view, support a cause, or participate in a movement. Too many environmental educators assume that they know all they need to know about the ecological aspects of environmental problems, and are concerned only with developing strategies and programmes for social change. They have become doctrinaire!

Of course, to some extent, they are right. We do have certain insights and knowledge, and we are unquestionably correct when we say that we must protect The Biosphere, for it is the support system on which all life depends-including human life. We must have clean air, clean water, and tillable soil. We must stem the tide of animal and plant extinctions. We need greenery, open space, and wilderness. We must reduce the stress placed on ecosystems by over-population and excessive consumption. Unfortunately, our insights on these issues tend to be superficial and our knowledge is often unnecessarily incomplete.

Much has been learned in the past decade about the operation of The Biosphere, but we educators have not stayed abreast of these developments and ideas. Thus, we bear considerable blame for the lamentable fact that little of this information has found its way into decision-making processes in governments and industry. If we are to fulfil our roles as communicators of information and knowledge, and if we are to effect change, protect The Biosphere, and help to develop ecologically sustainable societies, we must become far more rigorous and disciplined in our scholarship. We must identify the ecological, socio-economic, political, and educational, imperatives, and focus our attention on them.

What do I mean by imperatives? An imperative 'expresses a command' and is 'mandatory'. An ecological imperative is a factor so basic that the ecological system cannot exist without it, or at least it cannot continue in its present state without due action. An economic or political imperative, similarly, would be a factor that is mandatory for the continuation of economic or political order. An educational imperative, then, would be something that is necessary for the effective communication of information and increase in human knowledge and/or understanding of some required action or circumstance. Obviously, one educational imperative for the Campaign is that it must focus on ecological, socio-economic, and political, imperatives. By doing so its messages will contain new information-information based on up-to-date facts; information that goes beyond the obvious, beyond the showy; information that has social, economic, and political, import; information that could effect changes in the way we perceive The Biosphere, and consequently changes in the way we manage our lives and 'do business'.

In New Delhi and at Lake Louise we asked workshop participants to identify and define ecological, socio-economic, political, and educational, imperatives. In both workshops-workshops held on opposite sides of the world, one in a developed country, the other in a country that is still developing_participants treated the ecological problems as 'given': 'We already understand the problems; let's get on with creating strategies for social change.' Yet the fatal flaw is still there. We still think we have all the information which we need, and that all we have to do now is to figure out how to package it and identify the power-structure to aim at as our audience. Yes, the flaw is still there, but it was weakened a bit in New Delhi and at Lake Louise, as we are now asking rigorous questions. If we continue to do so, we will soon learn that we do not yet adequately understand ecological imperatives, and from there it ought to be possible to move forward.

The following should be our strategy—at once global, regional, and local:

1. Recognize that we don't have all the answers and that better information could lead to more compelling educational materials and programmes than are currently in operation.

2. Focus on the basics and hence on imperatives-the underlying factors that maintain social and ecological systems. If we can protect these, many of the other problems will be taken care of in the process.

3. Act locally: Educational materials and programmes must be generated in the particular area where they are to be used. They must be society- and culture-specific.

4. Think globally: There must be a global network for the exchange of information and ideas. There must also be opportunities for direct interaction between persons from different parts of the world, because we are human beings with experiences and ideas and feelings that go beyond our written words. We are, moreover, gregarious beings, needing to touch one another, for only in that way can we truly understand and communicate fully. 
At Lake Louise, there were calls again for a Global Strategy for Environmental Education. But I submit that we now have such a strategy: It is in place and has already begun functioning. Unlike other global strategies, this is a 'grassroots' or 'bottom-upwards' strategy. It is a network-a network of professional education societies and individuals who are committed to rigour in their relentless quest for knowledge. It is also a strategy for developing ecologically sustainable societies. It is the International Society For Environmental Education and its sister organization the World Council For The Biosphere.

CRAIG B. DAVIS, Secretary-General of WCB-ISEE Director, School of Natural Resources

The Ohio State University

2021 Coffey Road

Columbus

Ohio 43210

USA.

\section{EDITORIAL}

\section{Violence Deplored: Substitute Due Respect for Life and The Biosphere}

$\mathrm{T}$ he World Council For The Biosphere (WCB) and its complementary 'twin sister' the International Society For Environmental Education (ISEE) are effectively placed in their proper, action-engendering context by WCB-ISEE Secretary-General Craig B. Davis in the preceding Guest Editorial and by WCB Councillor Lynton K. Caldwell in his pivotal paper of this issue. WCB and ISEE are at once leading offshoots and active adopters of our World Campaign for The Biosphere, on which enough has already appeared in these columns. At the same time WCB and ISEE-which are especially featured in the four following contributions and elsewhere in this issue of our Journal-are auguries of another need (some would call it an imperative, if our world is to survive), namely peaceful co-existence rather than violent confrontation.

In advancing the concept of Our Biosphere as a harbinger of 'peace for all Mankind', we should re-emphasize the four basic truths that we, Mankind, being specimens of Homo sapiens of whatever kind, colour, denomination, or dimensions: (1) are an integral part of The Biosphere to which we now collectively contribute a major portion of its biomass while controlling very much more, (2) that The Biosphere is an integrated whole which can be jeopardized only at the greatest possible risk, (3) that Mankind and Nature are utterly dependent on The Biosphere's health and productivity for the wherewithal of life and that of future generations, but (4) that we are threatening this only life-support more and more gravely with our ever-increasing numbers and demophoric impact.

The main threats we have also detailed more than once in these columns or elsewhere, and in many cases spell out again in the next-following paper. But have we made enough of the waves of violence and terrorism which shock the world so frequently nowadays that we risk getting accustomed to them and even complacently apathetic about them? That seems to be a concomitant danger which must be faced, even as we deplore violence and plead for due respect for life and property.

Yet what are the origins of this widespread violence and why does it seem to get worse and worse? We have pondered on various possible explanations and come back to our usual basic one of 'too many people'. However, the increases in lawlessness seem to have been far more rapid of late than increases in human population or even its pressures (demophora) alone, and have involved countries in which the population is stable or even decreasing. Consequently another explanation must be sought, and we believe the media-especially television-are gravely to blame.

If one looks at almost any television show on either side of the Atlantic or often further afield nowadays, one will risk being confronted by all manner of violence or sheer nastiness - to the extent that such horrors will inevitably in time seem to be a normal way of life or at least a facet of modern life. That being so, especially the possessors of impressionable young minds will regrettably be apt to go out and perpetrate what they may have thus been moulded into regarding as 'the normal way of life', however pervertedly debauched or actually criminal it may be. Numerous instances have indeed been reported of such emulation, with perpetrators often admitting that they had got their ideas or even guidance from television, cinema, or the press-sometimes for quite heinous crimes, including planned murder (see, for example, the horrifying account in Reader's Digest, January 1983, pp. 49-53). This deplorably dangerous situation surely needs remedying, and could well be remedied, by suitable laws and their proper enforcement.

Instead of these horrors we would foster due respect for life, and due reverence for the solidly good things which it can offer.To be sure, it is easy to say that from our vantage-point of relatively good fortune; but circumstances have not always been easy, and latterly it has become increasingly difficult to maintain a multiplicity of joblets of which editing this Journal is only one. Yet we feel that the afore-mentioned concept of Our Biosphere as a harbinger of peace (as it can certainly be of prosperity if given a proper chance) can be of great spiritual solace and even practical help.

In terms of the ethics of human individuality cum interdependence: if all farmers, landowners, foresters, horticulturists, aquaculturists, and others responsible for the healthful maintenance of however small an area of our planet, would come to view it also as an integral and hence important part of The Biosphere, they would be the more likely to look after it as diligent stewardswhereupon, we believe, there would be less inclination to strife and violence of all kinds, including the waging of wars. Such concern should be felt and expressed with quasi-religious fervour and, with due reverence for life, could take the place of more orthodox religions and traditional disciplines whose widespread erosion is another sad feature of our techno-scientific age. 